\title{
How a Key Currency Functions as an International Liquidity Provision and Insurance System*
}

\author{
Masayuki Otaki \\ Institute of Social Science, University of Tokyo, Tokyo, Japan \\ Email: ohtaki@iss.u-tokyo.ac.jp
}

Received December 9, 2012; revised January 10, 2013; accepted February 12, 2013

\begin{abstract}
Although some previous studies assert that the selection of a key currency is a kind of hysteresis dominated by contingencies, historical evidence suggests that this selection depends on the following two plausible and inevitable economic factors that this study examines: overwhelming industrial power and the possession of huge amounts of foreign assets and gold. Based on the fulfillment of these economic factors, the key-currency country receives rents in return for bearing the sovereign risk and supplying sufficient liquidity to the countries within its network that accept its currency. Thus, the key-currency system can be regarded as an international liquidity provision and insurance system that relies on the economic power of the key-currency country.
\end{abstract}

Keywords: Key Currency as an Insurance System; Rents from Issuing a Key Currency; International Liquidity; Sovereign Risk

\section{Introduction}

Key currencies such as the dollar, previously sterling, are indispensable for facilitating the international clearing of currency transaction. However, the process of the agreeing on the selection of the key currency to be used is not necessarily clear.

Some previous research (e.g., Matsuyama, Kiyotaki, and Matsui [1]) suggests that the key currency is selected by an inertia that arises from certain contingencies (i.e., a kind of hysteresis). ${ }^{1}$ However, the bulk of the historical evidence indicates that the selection of a key currency depends on the following two definitive factors.

First, the key-currency country possesses overwhelming industrial power that can monopolize the global marketplace. This degree of power alleviates the anxiety that the currency mutates only on paper. In other words, the money issued by the key-currency country is implicitly and sufficiently endorsed by the durable the goods it produces. In this sense, holding the key currency can play roles of liquidity and insurance provision for the other countries that face serious domestic production or supply risks (hearafter surrounding countries) such as sovereign risk.

Second, key-currency countries own huge amounts of foreign assets and gold, which, in addition to the huge potential supply capacity, helps both maintain the sub-

\footnotetext{
${ }^{*}$ The author is grateful to Dr. Trevor Chamberlain for his thoughtful and constructive comments.

${ }^{1}$ See Fukao and Otaki [2] for a rigorous definition of hysteresis.
}

stantial value of the key currency and enhance its circulation. These factors tends to favor surrounding countries that accept the key currency.

On the other hand, the key-currency country also excersises its prerogative including making decision on seigniorage and the fees of financial transactions. Thus, the key-currency system can be regarded as a kind of international liquidity provision and insurance system, in which the key-currency country is implicitly in charge of an insurance company and surrounding countries its her insurants. In other words, the rents received from issuing the key currency are the insurance fee, while the key currency that is circulated among and within surrounding countries represents the insurance security that is attached to maintaining high levels of international liquidity.

In light of the foregoing and following Otaki [3-5], this paper aims to fill the gap in the literature by constructing an open-economy macroeconomic model that provides a rigorous microeconomic foundation for a key-currency country.

The structure of the remainder of the paper is as follows. Section 2 presents the model that describes the economies of $n+1$ countries ( $n$ is the number of surrounding countries and can adequately represent large numbers, and 1 is the number of the key currencies), to demonstrate how the aforementioned implicit insurance system works. Section 3 deals with the comparative statics and the welfare analysis of the change in keycurrency supply. Section 4 contains the brief con- 
cluding remarks.

\section{The Model}

\subsection{Structure of the Model}

The presented model is a two-period overlapping-generations model with infinite horizon based on Otaki [3]. Each country produces the same differentiated goods by monopolistic entrepreneur $i z$, where $i$ generically refers to the characteristics of the country and $z$ refers to those of the good. Each country contains $m \lambda_{i}$ entrepreneurs who receive all earned profits and $(1-m) \lambda_{i}$ employees whose incomes come from only nominal wages.

The key-currency country $K$ is differentiated from surrounding countries $S$ only by its huge population $\lambda_{k}$ per generation, while the population of each $S$ is limited by $\lambda_{s}\left(n \lambda_{s}=\lambda_{k}\right)$. Since the only production resource is labor, which is supplied by the younger generation, this asymmetric assumption implies that the economy of the key-currency country holds a huge potential production power compared with surrounding countries.

In addition, each surrounding country faces a serious supply shock, though temporary, or sovereign risk. However, the key-currency country runs no such risk, implying that its production process is far more reliable. For simplicity, when this supply shock is induced, the surrounding country cannot produce any goods. The probability of such a disaster is assumed to be $\varepsilon(0<\varepsilon \ll 1)$.

All individuals possess an identical lifetime utility function $U_{i}$ :

$$
\begin{aligned}
U_{i} & \equiv U\left(c_{i j t}^{1}, c_{i j t}^{2}\right)-\delta_{i j} \alpha, \\
c_{i j t}^{h} & \equiv\left\{\sum_{z=1}^{h}\left[c_{i j t}^{l}(z)\right]^{1-\eta^{-1}} \mathrm{~d} z\right\}^{\frac{1}{1-\eta^{-1}}}, \quad \eta>1,
\end{aligned}
$$

where $U$ is a well-behaved homothetic function and $c_{i j t}^{h}(z)$ denotes the consumption of $\operatorname{good} z$ by individual $j$ aged $l$ in the $i$-th country during period $t . \alpha$ is the disutility of labor, and $\delta_{i j}$ is a definition function that takes the value if unity when individual $j$ in country $i$ participates in the labor force and zero when he/she is unemployed. One unit labor produces one unit of a $\operatorname{good}^{2}$

In this situation, an incentive for insurance emerges between the key-currency country and surrounding countries. In other words, instead of allowing the domestic circulation of the key currency and handing over rents received from issuing their own currencies, surrounding

\footnotetext{
${ }^{2}$ The assumption that the utility functions of all individuals in the world are identical is restrictive. Nonetheless, our main concern here is to show that the imbalance in the current account, namely, the international capital movement, is caused without a difference in inflation rates across countries owing to the difference in time preferences. From this perspective, the aforementioned assumption is admissible for simplification purpose.
}

countries import goods in exchange for the key currency. Thus, an almost one-sided capital flow (deficit in the key-currency country, surplus in surrounding countries) emerges, and the key-currency system thus becomes sustainable by creating such an incentive.

\subsection{Construction of the Model}

\subsubsection{Individuals}

Since the lifetime consumption utility function is homothetic, the corresponding expenditure function $\Psi$ is represented as

$$
\begin{aligned}
& \Psi \equiv \psi\left(p_{t}, p_{t+1}\right) f(u), \\
& p_{t} \equiv\left\{\sum_{z=1}^{h}\left[p_{t}(z)\right]^{1-\eta} \mathrm{d} z\right\}^{11-\eta},
\end{aligned}
$$

where $u$ is the fixed utility level, and $\psi(\cdot)$ is the increasing linear homogenous function of $\left(p_{t}, p_{t+1}\right)$. To introduce risk aversion into the utility function, we assume that $f^{\prime \prime}>0$.

As long as economies are located at the imperfect employment equilibrium, as Otaki $[3,4]$ shows, the equilibrium nominal wage is kept equal to the nominal reservation wage $W_{t}^{R}$. The latter wage is easily induced from Equation (2) as

$$
W_{t}^{R}=\psi\left(p_{t}, p_{t+1}\right) f(\alpha) .
$$

\subsubsection{Firms}

From the assumption about the instantaneous utility function, the demand function $D_{z t}$ for good $z$ that is monopolistically produced by a certain firm becomes

$$
D_{z t} \equiv\left[\frac{p_{t}(z)}{p_{t}}\right]^{-\eta} y_{t},
$$

where $y_{t}$ is real GDP in terms of current goods. From the profit maximization condition and Equation (3), we obtain the following fundamental difference equation concerning the evolution of the price level:

$$
\begin{aligned}
p_{t} & =\frac{\psi\left(p_{t}, p_{t+1}\right) f(\alpha)}{1-\eta^{-1}}=\frac{p_{t} \psi\left(1, \pi^{*}\right) f(\alpha)}{1-\eta^{-1}}, \\
\pi^{*} & \equiv \frac{p_{t+1}}{p_{t}} .
\end{aligned}
$$

We must note that Equation (4) holds for all countries including the key-currency country. Accordingly, the purchasing power of the key currency can be preserved worldwide because the same equilibrium inflation rate $\pi^{*}$ is attained in every country, independent of the nominal money supply of the key currency. ${ }^{3}$

In other words, the fixed exchange rate system is

${ }^{3}$ Otaki [5] defines money as credible in a situation where the nominal money supply does not affect the price level. 
sustainable even under perfect capital mobility. For simplicity, we assume that the nominal exchange rate is fixed at unity and the initial absolute prices in the key-currency area are the same.

\subsubsection{Governments}

The government of the key-currency country adopts the following two segregated monetary-fiscal policies:

1) The key-currency country supplies domestic money through wasteful government expenditure. The expenditure per capita amounts to $\lambda_{k} G\left(\equiv \lambda_{k} \cdot p_{t+j} g\right){ }^{4}$

2) Surrounding countries receive money by importing the composite good defined by Equation (1). All imported goods are transferred to younger residents in the key-currency country equally.

To keep the analysis as simple and clear as possible, we confine the discussion to the stationary equilibrium. Hence, the monetary authority in the key-currency country keeps the real money supply constant in both the keycurrency and surrounding countries. Let us denote these values as $m \lambda_{k} m^{d}$ and $n \lambda_{s} m^{f}$, respectively. Furthermore, the number of surrounding countries $n$ is assumed to be large enough that the law of large numbers approximately holds.

\subsection{Market Equilibrium and International Liquidity Provision}

Three kinds of markets exist in our model: goods markets, labor markets, and money markets. The scope of this study is the former two markets as per Walras' Law. Each labor market is in interior equilibrium if the equilibrium nominal wage is equal to the nominal reservation wage $W_{t}^{R}{ }^{5}$ Eventually, only the analysis concerning goods markets remains.

The equilibrium condition for goods markets is represented by the following two-stage game. At the first stage, the key-currency and surrounding country negotiate for the international implicit insurance. The second stage determines how much the key-currency country should provide the international liquidity to surrounding countries.

To solve the perfect equilibrium, we must begin with solving the solution of the second stage. Since the lifetime utility function of the consumption stream is assumed to be homothetic, the consumption function of a younger individual in each country $C_{i}$ is

$$
C_{i} \equiv c\left(\pi^{*}\right) y_{i}^{d}, \quad i=k \text { or } s,
$$

where $y_{i}^{d}$ is the per capita disposable income of country $i$.

\footnotetext{
${ }^{4}$ We adopt the assumption of wasteful expenditure for simplicity. Even if the government contributes to the economic welfare, the obtained results are unchanged.

${ }^{5}$ For the properties of the boundary equilibrium, see Otaki [5].
}

The equilibrium of the aggregate goods market in each surrounding country is conditional on whether the emergent sovereign risk is induced. In other words,

$$
y_{s}=\left\{\begin{array}{l}
c\left(\pi^{*}\right)\left[y_{s}-E\right]+m^{f}+E, \text { with probability } 1-\varepsilon, \\
m^{f}+s, \quad \text { with probability } \varepsilon,
\end{array}\right.
$$

where $y^{s}$ is the real GDP per capita and $E$ represents exports to the key-currency country, and, $y_{s}-E$ thus denotes its disposal income per capita.

By solving (6) for state 1 , we obtain

$$
y_{s}-E=\frac{m^{f}}{1-c\left(\pi^{*}\right)} \Leftrightarrow E+\frac{m^{f}}{1-c\left(\pi^{*}\right)}=y_{s} .
$$

Since the sum of the rents received by the keycurrency country $E$ and each surrounding country's disposal income per capita $\frac{m^{f}}{1-c\left(\pi^{*}\right)}$ is always equal to each surrounding country's real GDP per capita $y_{s}$, Equation (6) implies that it is beneficial for both countries to provide sufficient liquidity $m^{f}$ to reach the full-employment equilibrium. Thus, this international liquidity guarantees the full-employment equilibrium in every surrounding country. Hence, we can set $y_{s}=1$ for all $s$. This is the solution of the second-stage game.

Next, we move to the first-stage game based on the obtained above result. The net rent from issuing the key currency $B$, which is equal to the current account deficit of the key-currency country, is

$$
B\left(m^{f}, s\right) \equiv[1-\varepsilon]\left[1-\frac{m^{f}}{1-c\left(\pi^{*}\right)}\right]-\varepsilon\left[m^{f}+s\right],
$$

where $s$ denotes the additional aid (or discount) in the case of the emergencies in a surrounding country.

Thus, by combining Equation (5), the equilibrium condition for the aggregate goods market in key-currency country is represented as

$$
\begin{aligned}
y_{k}+B\left(m^{f}, s\right) & =c\left(\pi^{*}\right)\left[y_{k}+B\left(m^{f}, s\right)\right]+g+\frac{1}{\pi^{*}} m^{d} \\
& =c\left(\pi^{*}\right)\left[y_{k}+B\left(m^{f}, s\right)\right]+m^{d},
\end{aligned}
$$

where $y_{k}$ is the per capita real GDP in the key-currency country. The third term of the right-hand side of Equation (9) is the per capita real expenditure of old individuals.

By solving Equation (9) on $y_{k}$, the equilibrium GDP of the key-currency country is represented as

$$
y_{k}^{*}=\frac{m^{d}}{1-c\left(\pi^{*}\right)}-B\left(m^{f}, s\right) .
$$


Note that the same amount of equilibrium GDP per capita $y_{k}^{*}$ decreases in line with imports from foreign countries $B$, while disposable income is fixed as long as the real domestic money supply $m^{d}$ remains constant. The reason for this is that the increment in the savings of younger individuals from real GDP should be entirely crowded out by the increase in imports funded by the net rent from the key-currency system, given that the total purchasing power of the government and older individuals is unchanged.

Since the expected indirect utility is a monotonously increasing function of disposable income, the expected utility of the key-currency country increases with $B(\cdot)$ as long as full employment is maintained by ample liquidity $m^{d}$ that satisfies $\frac{m^{d}}{1-c\left(\pi^{*}\right)}=1+B$. Accordingly, the key-currency system attains the worldwide fullemployment equilibrium. In other words, the keycurrency system serves as the best international liquidity provision system. ${ }^{6}$

From Equation (7), the indirect expected utility of a surrounding country is ${ }^{7}$

$$
\tilde{U}^{s} \equiv[1-\varepsilon] f^{-1}\left(\frac{m^{f}}{1-c\left(\pi^{*}\right)}\right)+\varepsilon f^{-1}\left(m^{f}+s\right) .
$$

From the law of large numbers, the key-currency country can become risk-neutral, and thereby the pay-off function is expressed by Equation (8).

Consequently, the key-currency system as an optimal contract of insurance system can be described by the following maximization problem.

$$
\max _{m^{f}, s} B\left(m^{f}, s\right) \text {, s.t. } \tilde{U}^{s} \geq \bar{U} .
$$

By using the above result, the Lagrangian $L$ of this problem is written as

$$
\begin{aligned}
& L\left(m^{f}, s, \lambda\right) \equiv[1-\varepsilon]\left[1-\frac{m^{f}}{1-c\left(\pi^{*}\right)}\right]-\varepsilon\left[m^{f}+s\right] \\
& +\lambda\left[[1-\varepsilon] f^{-1}\left(\frac{m^{f}}{1-c\left(\pi^{*}\right)}\right)+\varepsilon f^{-1}\left(m^{f}+s\right)-\bar{U}\right]
\end{aligned}
$$

where $\lambda$ is the Lagrangian multiplier.

The optimal contract is illustrated by point $E_{1}$ in Figure 1. $U_{1}$ is the indifference curve of a surrounding country that corresponds to the utility level $\bar{U} \cdot I_{1}$ and $I_{2}$ are the iso-profit lines of the key-currency country.

\footnotetext{
${ }^{7}$ Note that the full-employment equilibrium is Pareto efficient, even if there is no additional utility gain from the increment in labor. This is because monopolistic profits increase with real GDP. See Otaki [3] for more detail.

${ }^{8}$ One may consider that each argument in $f^{-1}(\cdot)$ should be divide by the price index $\psi\left(1, \pi^{*}\right)$. However, note that the preference ordering is invariant by the multiplicative transformation of each argument.
}

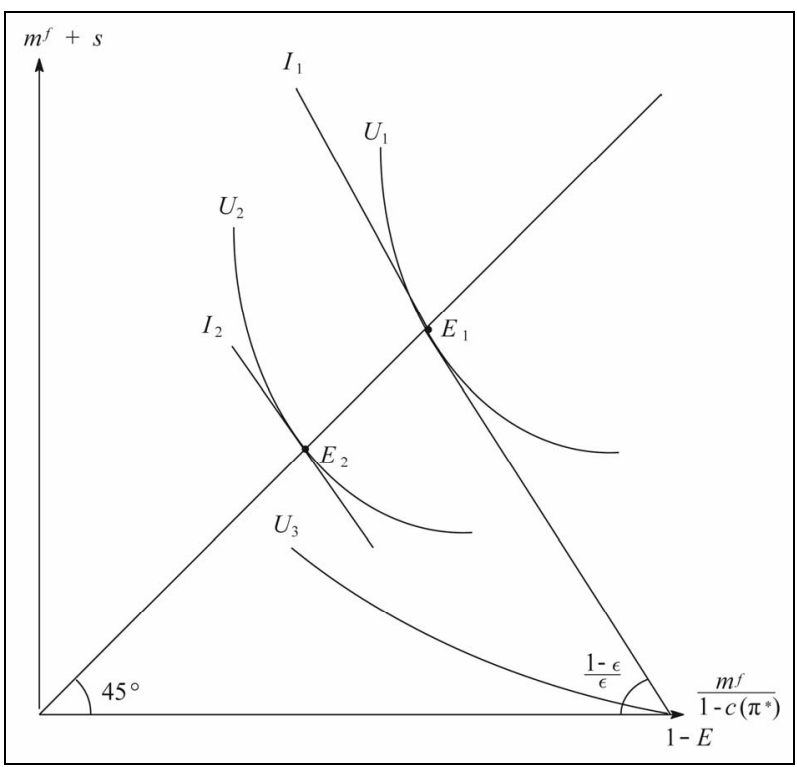

Figure 1. Key-currency system as implicit insurance contract.

The line bottom left of the figure (e.g., $I_{2}$ ) indicates higher profits. It is clear from Figure 1 that sovereign risk is completely hedged at solutions for Equation (12) such as points $E_{1}$ and $E_{2}$ that each surrounding country receives a fixed income regardless which of the two states occurs. It is clear from indifference curves $U_{1}$ and $U_{3}$ that a surrounding country also becomes better off by such an insurance.

\section{The Persistent Imbalance of the Current Account and the Exchange Rate}

In this subsection, we apply simple comparative statics on the bargaining power of the key-currency country in order to consider why the persistent current account deficit of the key currency country is sustainable.

As discussed about Equation (8), the persistent current account deficit is closely connected with the profits from issuing the key currency in the form of an implicit insurance device. The expected profits from each surrounding country is calculated, with a probability of one, as

$$
B^{*} \equiv[1-\varepsilon]\left[1-\frac{m^{f *}}{1-c\left(\pi^{*}\right)}\right]-\varepsilon\left[m^{f *}+s^{*}\right] .
$$

The first and second terms in (14) represent the average imports from and average exports to a surrounding country. Thus, Equation (14) expresses the net rent received (insurance due) from issuing the currency, respectively. In turn, the net rent is always equal to the current account deficit of the key-currency country. To summarize, the reason why the key-currency country can sustain a persistent current account deficit based on the 
rents recieved from issuing its currency, which is endorsed by its overwhelming industrial and political power.

When the key-currency country's power is strengthened by political decisions, the equilibrium contract moves to point $E_{2}$ in Figure 1. This figure clearly shows that the rents received from issuing the currency increases and that the current account deficit thus becomes prominent. ${ }^{8}$

\subsection{Vulnerability of the Key-Currency System}

Insurance is ineffective against macroeconomic synchronized shocks, with war the most illustrative example. In World War II, the UK was heavily indebted to the US for the munitions for Egypt, India, and herself. In addition to the weakened industrial power relative to the US, such indebtedness resulted in a serious outflow of gold from the UK. This is considered to be one of the primary reasons that the UK abdicated the right to be a key-currency country.

Although, this example may be beyond the strict scope of this theory because the unlimited emancipation of capital flow strengthens the international cohesion of the business cycle in the key-currency country. It is expected that the key-currency country has much difficulty sustaining the system in such a situation.

\subsection{The Key-Currency System and Optimal Currency Area}

Mundell's [7] seminal work on optimal currency areas argues that factor mobility, including labor force mobility, is indispensable for constructing an optimal currency area. However, it also implies that exogenous shocks are synchronized within economies that belong to the area. In such a case, the key-currency system is unsuitable because such a risk-sharing system would not work.

Furthermore, it is not necessary for the autonomous currency area to be allied to a huge economy such as the key-currency country as Otaki [8] indicates. Even if each economy is small, as long as factor mobility is perfect, such economies can unionize a currency area. As such, a currency area may remain a limited body unlike the key-currency system.

\section{Concluding Remarks}

By describing the key-currency system as a kind of international liquidity provision and insurance system against idiosyncratic sovereign risk, this paper draws three main conclusions.

\footnotetext{
${ }^{8}$ The problem of the ownership of the worldwide currency rent is very sensitive. For example, at the Bretton Woods conference, the proposal for a common world currency, Unitas, was rejected. Furthermore, Keynes strived hard to maintain sterling as a key currency (see Moggridge [6, Ch. 28, 29]) for details.
}

First, as an international liquidity provision system, the key-currency system works well because there is a common incentive to maximize the expansion of every country's economy. After sufficient levels of the key currency in order to attain the full-employment equilibrium, joining countries divide their fruits in accordance with the implicit insurance contract.

Second, risk is completely hedged under the keycurrency system. As risk increases, the key-currency country demands more higher fees to use its currency, resulting in a decrease in the disposable incomes of surrounding countries. However, in turn, this indicates that the trade balance deficit in the key-currency country becomes prominent. In this sense, reducing the sovereign risk is crucial for developing the economy.

Finally, we must consider the threat of serious macroeconomic shocks. When surrounding countries simultaneously fall into serious slumps and move to convert the key currency into goods (or gold), the key-currency system is unsustainable. Instead, a common currency area is recommended in such a circumstance.

\section{REFERENCES}

[1] K. Matsuyama, N. Kiyotaki and A. Matsui, "Toward a Theory of International Currency," Review of Economic Studies, Vol. 60, No. 2, 1993, pp. 283-307. doi: $10.2307 / 2298058$

[2] K. Fukao and M. Otaki, "Accumulation of Human Capital and the Business Cycle," Journal of Political Economy, Vol. 101, No. 1, 1993, pp. 72-99. doi:10.1086/261866

[3] M. Otaki, "The Dynamically Extended Keynesian Cross and the Welfare Improving Fiscal Policy," Economics Letters, Vol. 96, No. 1, 2007, pp. 23-29. doi:10.1016/j.econlet.2006.12.005

[4] M. Otaki, "A Welfare Economic Foundation for the FullEmployment Policy," Economics Letters, Vol. 102, No. 1, 2009, pp. 1-3. doi:10.1016/j.econlet.2008.08.003

[5] M. Otaki, "A Pure Theory of Aggregate Price Determination," Theoretical Economics Letters, Vol. 1, No. 3, 2011, pp. 122-128. doi:10.4236/tel.2011.13026

[6] D. E. Moggridge, "Maynard Keynes: An Economist's Biography," Routledge, London, 1992.

[7] R. Mundell, "A Theory of Optimum Currency Areas," American Economic Review, Vol. 51, No. 4, 1961, pp. 509-517.

[8] M. Otaki, "A Microeconomic Foundation for Optimum Currency Area: The Case for Pefect Capital Mobility and Immobile Labor Forces," Theoretical Economics Letters, Vol. 2, No. 4, 2012, pp. 399-403. doi:10.4236/tel.2012.24073 